\title{
Validation of Doubly Labeled Water for Assessing Energy Expenditure in Infants
}

\author{
P. J. H. JONES, A. L. WINTHROP, D. A. SCHOELLER, P. R. SWYER, J. SMITH, R. M. FILLER, \\ AND T. HEIM
}

Clinical Nutrition Research Unit, Department of Medicine, University of Chicago, Chicago, Illinois 60637 and Departments of Surgery, Pediatrics and Nutritional Sciences, University of Toronto, and the Research Institute, Hospital for Sick Children, Toronto, Ontario, Canada

\begin{abstract}
Previous studies show that the doubly labeled water method is accurate for measuring energy expenditure in the adult human. To validate this method in infants, carbon dioxide production rate and energy expenditure were measured for 5 to 6 days by doubly labeled water (DLW) and periodic open circuit respiratory gas exchange (RGE) in 10 blinded studies in nine infants following abdominal surgery. Infants were maintained on consistant oral or parenteral nutrition prior to and during study. This avoided diet-related changes in baseline isotopic enrichment of body water which could theoretically contribute to significant errors in calculation of carbon dioxide production rate. For DLW, insensible water loss was assumed to be proportional to respiratory volume and body surface area, where the former was predicted from carbon dioxide production rate. Insensible water loss thus calculated averaged $18 \%$ of water turnover. Rates of carbon dioxide production measured by DLW were not significantly different from that of RGE (10.4 \pm 1.1 and 10.5 \pm $0.9 \mathrm{l} / \mathrm{kg} / \mathrm{day}$, mean $\pm \mathrm{SD}$, respectively). Energy expenditure was calculated using respiratory quotients from dietary intake (DLW:DIET) and RGE (DLW:RGE) data. There was no significant difference between energy expenditure determined by DLW (DLW:DIET and DLW:RGE) and that measured by RGE $(58.5 \pm 6.1,56.8 \pm 6.1$, and 57.3 $\pm 5.1 \mathrm{kcal} / \mathrm{kg} / \mathrm{day}$, mean $\pm \mathrm{SD}$, respectively). Rate of carbon dioxide production, DLW:diet, and DLW:RGE calculated by DLW differed from corresponding RGE values by $-0.9 \pm 6.2,-1.1 \pm 6.1$, and $1.6 \pm 6.2 \%$, mean $\pm \mathrm{SD}$, respectively. These findings demonstrate the validity of the doubly labeled water method for determining energy expenditure in infants without concurrent water balance studies. (Pediatr Res 21: 242-246, 1987)
\end{abstract}

\section{Abbreviations}

STPD, dry standard temperature and pressure RQ, respiratory quotient

SMOW, standard mean ocean water

In the infant, accurate measurement of energy expenditure is of primary importance when estimating energy requirements as food energy must not only meet the needs of maintenance

Received July 17, 1986; accepted October 17, 1986.

Address correspondence Dale A. Schoeller, Clinical Nutrition Research Unit, Box 400, Department of Medicine, 5841 S. Maryland Ave, University of Chicago, Chicago, IL, 60637.

Supported by the National Institutes of Health (NIH AM 30031) and the Medical Research Council of Canada (MT 7277). P.J.H. and A.L.W. held Research Fellowships from the Medical Research Council of Canada. metabolism, but also the energy costs of rapid growth. To date, respiratory gas exchange has been the method of choice for measuring energy expenditure in infants and together with anthropometric data, serves as the basis for current knowledge of neonatal energy requirements (1).

The doubly labeled water method allows for integral, noninvasive, and nonrestrictive measurement of total energy expenditure over extended periods. This method offers the advantage of simplicity of use in field studies as the procedure requires only urine and saliva sampling following administration of isotope. Also, total energy expenditure can be determined over a period of several days while the subject remains in his or her normal environment. Thus, doubly labeled water has the potential to extend capabilities and compliment current techniques for measuring energy expenditure.

Doubly labeled water has been validated in adults against respiratory gas exchange (2-4) and energy/intake balance (5) and has been shown to have an accuracy of 2 to $6 \%$ and a precision of 6 to $8 \%$. The method has recently been applied to the infant (6), however, not without concurrent water balance studies. Infant water turnover is greater than that of the adult, introducing potential error in the calculation of isotope elimination rates. Moreover, in the growing infant it is unknown if all of the assumptions of the doubly labeled water method remain valid.

The purpose of the present study was to determine the accuracy of doubly labeled water for measuring energy expenditure in infants by comparison of this technique with periodic open circuit respiratory gas exchange in an inpatient group of infants following surgery.

\section{METHODS}

Subjects. Ten blinded studies were performed in nine infants. Table 1 summarizes demographic data for the 10 studies. Infants were recovering from abdominal surgery and were afebrile during study. Mean gestational age was $38 \pm 2$ wk (mean \pm SD) postnatal age was $17 \pm 19$ days, and study weight was $3.1 \pm 0.7$ $\mathrm{kg}$. One infant (subject 2) was substantially older than the rest of the group. Informed written consent was obtained from parents prior to study. All procedures were approved by the Human Experimentation Committee of the Hospital for Sick Children.

Energy expenditure was measured for 5 or 6 days during which time periodic respiratory gas exchange was determined. Infants were maintained on consistent parenteral or oral nutrition for at least 4 days prior to and throughout the study period. Nutrient intake was recorded daily.

Respiratory gas exchange measurements. Oxygen consumption, carbon dioxide production, and respiratory quotient of infants were measured by computerized open circuit respiratory gas exchange analysis (7). Infants' heads were enclosed in a perspex hood through which room air was ventilated at 1 liter/ 
Table 1. Demographic data of infants studied

\begin{tabular}{|c|c|c|c|c|}
\hline Subject & Diagnosis & Days postsurgery & $\begin{array}{c}\text { Age } \\
\text { (days) }\end{array}$ & $\begin{array}{c}\mathrm{Wt} \\
\text { (average kg during study) }\end{array}$ \\
\hline 1 & Ileal atresia & 10 & 11 & 2.57 \\
\hline $2 *$ & Gastroesophageal reflux & 10 & 49 & 3.89 \\
\hline $2 b^{*}$ & Gastroesophageal reflux & 18 & 57 & 4.16 \\
\hline 3 & Diaphragmatic hernia & 7 & 7 & 3.44 \\
\hline 4 & Diaphragmatic hernia & 8 & 9 & 2.59 \\
\hline 5 & Gastroschisis & 9 & 9 & 2.79 \\
\hline 6 & Duodenal atresia & 4 & 6 & 1.92 \\
\hline 7 & Meconium ileus & 8 & 14 & 4.03 \\
\hline 8 & Gastroschisis & 5 & 6 & 2.98 \\
\hline 9 & Omphalocele & 6 & 6 & 3.39 \\
\hline Mean & & 8.5 & 17.4 & 3.18 \\
\hline$\pm \mathrm{SD}$ & & 3.9 & 19.0 & 0.72 \\
\hline
\end{tabular}

* Subject studied twice.

$\mathrm{kg} / \mathrm{min}$. Ventilation rate was measured using a mass flow meter (F112 MFM, Fielding Crossman and Assoc., Willowdale, Ontario, Canada). Air leaving the hood was approximately $0.5 \%$ depleted in oxygen and $0.5 \%$ enriched in carbon dioxide. This air was passed through dual channel paramagnetic oxygen (Servomex, Taylor Analytics, Crowborough, Sussex, England) and infrared carbon dioxide (LB-2, Beckman, Schiller Park, IL) analyzers. Rates of gas exchange were determined from the differences in oxygen and carbon dioxide concentrations between air entering and leaving the hood, together with flow rate data. Gas exchange volumes were corrected to STPD conditions. Additional corrections were performed for volume changes due to variation of RQ from 1. Analyzers were calibrated daily using purified reference gas standards. Weekly calibration was carried out using butane combustion ( $R Q=0.615)$.

The temperature of the respiratory gas exchange facility was adjusted within $1^{\circ} \mathrm{C}$ of that of wards where infants resided. Facility humidity was identical to that of the wards. This was done to insure that energy expenditure measured during the period of respiratory gas analysis was representative of total energy expenditure over the 5- to 6-day period. In addition, each infant was maintained within the thermoneutral range (8) by continuous monitoring of environmental temperature and infants' core and mean skin temperatures. Therefore energy requirements for thermoregulation should be minimized.

During the measurement periods urinary nitrogen excretion was determined, permitting calculation of nonprotein $R Q$. Global energy expenditure was determined using the Lusk equation (9):

$$
\mathrm{EE}=[4.686+(\mathrm{RQ}-0.707 / 0.293) * 0.361] * \mathrm{r} 02
$$

where $\mathrm{EE}$ is energy expenditure $(\mathrm{kcal} / \mathrm{min})$ and $\mathrm{rO} 2$ is rate of oxygen consumption ( $1 / \mathrm{min})$.

Respiratory gas exchange measurements were performed for periods of 2 to $6 \mathrm{~h}$ on at least two occasions during the 5- or 6day study. All measurements were performed during morning or afternoon. Average energy expenditure for the 5-to 6-day period was calculated from the time weighted average of the repeated measurements.

Doubly labeled water. On the day prior to study, each infant was administered $0.1 \mathrm{~g} / \mathrm{kg}$ body weight ${ }^{2} \mathrm{H}_{2} \mathrm{O}$ (99.8 atom \% excess, Argonne Special Materials, Argonne, IL) and $1.42 \mathrm{~g} / \mathrm{kg}$ body weight $\mathrm{H}_{2}{ }^{18} \mathrm{O}$ (17.59 atom \% excess, Mound Laboratories, Miamisburg, $\mathrm{OH}$ ), either per os or through a single lumen nasogastric tube. Nasogastric tubes were then flushed with 5-ml sterile water. At $1 \mathrm{~h}$ postdose tubes were aspirated to collect, and correct for, unabsorbed label in the gastric contents. After at least three voids, and at least $3 \mathrm{~h}$ postdose, serial urine samples were collected for ${ }^{18} \mathrm{O}$ analysis. Body water volume was estimated from the dilution space of ${ }^{18} \mathrm{O}$. Total body water was corrected for both nasogastric loss of label and new water intake between dosing and urine sample collection. If body water volumes calculated from serial samples disagreed by greater than $2 \%$, as occurred in four cases, samples were reanalyzed. The following morning a further urine sample was collected marking the start of the doubly labeled water energy expenditure period. Additional samples were collected on days 2 or 3 and days 5 or 6 . These samples were analyzed for both ${ }^{2} \mathrm{H}$ and ${ }^{18} \mathrm{O}$ enrichment. On the final day of the energy expenditure period $0.6 \mathrm{~g} / \mathrm{kg}$ body weight $\mathrm{H}_{2}{ }^{18} \mathrm{O}$ was administered nasogastrically and total body water volume again determined as described above.

For determination of deuterium enrichment samples of urine were vacuum distilled across a $700^{\circ} \mathrm{C}$ oven containing uranium turnings to produce hydrogen gas (10). The hydrogen was analyzed for deuterium enrichment on a triple inlet Nuclide 3-60 isotope ratio mass spectrometer as previously described (11). This instrument was calibrated using three reference gases and results were expressed as enrichment per mil versus SMOW. The analytical error of the mass spectrometer is less than $1.5 \%$ of expected enrichment differences at the indicated doses. Fluid samples were also equilibrated with $1 \mathrm{ml}$ of carbon dioxide at $25^{\circ} \mathrm{C}$ for $48 \mathrm{~h}$. This carbon dioxide was isotopically analyzed for ${ }^{18} \mathrm{O}$ enrichment following cryogenic isolation. Analyses for ${ }^{18} \mathrm{O}$ enrichment were performed on a dual-inlet Nuclide 3-60 isotope ratio mass spectrometer and expressed as per mil versus SMOW as previously described (12). From the indicated doses of $\mathrm{H}_{2}{ }^{18} \mathrm{O}$ the predicted analytical error is less than $1 \%$ of expected enrichment differences.

Total body water was calculated from the distribution space of ${ }^{18} \mathrm{O}$ which was derived from its enrichment relative to the predose urine. This distribution space was assumed to be $1 \%$ larger than the total body water pool size (12). Total body water was corrected for both nasogastric loss of label and for water volume consumed during the interval between dose administration and sampling. Corrections were also made at the end of the energy expenditure periods for the lower enrichment of incoming water in relation to the body water pool.

Carbon dioxide production rate was calculated by the two point method utilizing ${ }^{2} \mathrm{H}$ and ${ }^{18} \mathrm{O}$ enrichment from samples at the beginning and end of the energy expenditure period. The equation used was as follows (10):

$$
\mathrm{rCO} 2=\frac{\mathrm{ko} * \mathrm{Do}-\mathrm{kh} * \mathrm{Dh}}{2 * \mathrm{f} 3}-\frac{\mathrm{f} 2-\mathrm{fl}}{2 \mathrm{f} 3} \mathrm{r}_{\mathrm{Gf}}
$$

where $\mathrm{rCO}_{2}$ is carbon dioxide production rate, ko and Do, and $\mathrm{kh}$ and $\mathrm{Dh}$, are elimination rates and dilution spaces for ${ }^{18} \mathrm{O}$ and deuterium, respectively. Factors $\mathrm{f} 1, \mathrm{f} 2$, and $\mathrm{f} 3$ are for fractionation of deuterium in water vapor, ${ }^{18} \mathrm{O}$ in water vapor, and ${ }^{18} \mathrm{O}$ in carbon dioxide, respectively. $\mathrm{r}_{\mathrm{G}}$ is the rate of isotopically fractionated gaseous water loss. 
Assuming that breath is saturated with water and contains $3.5 \%$ carbon dioxide then breath water $=1.77 \mathrm{rCO}_{2}$. Transcutaneous water (nonsweat) has been estimated at $0.18 \mathrm{~g} / \mathrm{min} / \mathrm{m}^{2}$ (13). Assuming in the present group of infants that $75 \%$ of skin surface area is exposed, then transcutaneous water losses would amount to about $80 \%$ of that lost as breath water. Thus:

$$
\mathrm{r}_{\mathrm{Gf}}=1.8 * 1.77 * \mathrm{rCO} 2
$$

then

$$
\mathrm{rCO} 2=0.445 \mathrm{~N}(1.01 * \mathrm{ko})-(1.04 * \mathrm{kh})
$$

where $\mathrm{N}$ is the mean of the initial and final total body water volume. Equation 4 differs from that proposed for the adult (10) because in the adult exposed skin surface area is assumed to be $50 \%$. The two equations, however, differ in their calculation of rCO2 by only $3 \%$. A urine sample from day 2 or 3 of the study period was analyzed for isotopic enrichment to serve as an internal check for elimination rates of ${ }^{18} \mathrm{O}$ and deuterium. Agreement between the energy expenditure for the 2- or 3-day period with that for the total period was required to be within $10 \%$. If not, isotopic analysis of samples was repeated. When agreement criteria were satisfied the energy expenditure value was unblinded and compared to that of respiratory gas exchange. One subject never met these criteria and thus was never unblinded or included in the following data. Energy expenditure was calculated using respiratory quotients derived both from respiratory gas exchange and nutrient intake data.

\section{RESULTS}

Table 2 summarizes total body water values and isotopic decay data for the 10 studies. Mean total body water was $2.34 \pm 0.47$ $\mathrm{kg}$ which represented $73.9 \%$ of body weight. Mean water turnover was $0.2024 \pm 0.027$. The mean differences between isotope decay rates was $0.0315 \pm 0.003$.

We tested for completeness of absorption of ${ }^{18} \mathrm{O}$ on eight occasions in six infants by measuring the ${ }^{18} \mathrm{O}$ enrichment of gastric aspirate $1 \mathrm{~h}$ after isotope administration. Mean recovery of unabsorbed label was $1.2 \pm 0.6 \%$ (mean $\pm \mathrm{SD}$ ) of dose administered.

Carbon dioxide production rates measured by doubly labeled water and respiratory gas exchange are presented in Figure 1. The carbon dioxide production rates for doubly labeled water were not significantly different from those of respiratory gas exchange $[10.4 \pm 1.1$ and $10.5 \pm 0.9 \mathrm{l} / \mathrm{kg} /$ day $($ mean $\pm \mathrm{SD}$ ), respectively]. The relative difference between doubly labeled water and respiratory gas exchange values was $-0.9 \pm 6.2 \%$.

Energy expenditure measured by doubly labeled water and respiratory gas exchange is shown in Figure 2. Mean energy expenditure values for doubly labeled water:diet RQ [58.5 \pm 6.1 $\mathrm{kcal} / \mathrm{kg} /$ day (mean $\pm \mathrm{SD}$ )] and doubly labeled water:respiratory

Table 2. Average total body water (TBW) and isotopic decay data for 10 studies

\begin{tabular}{cccc}
\hline Subject & $\begin{array}{c}\text { TBW } \\
(\mathrm{kg})\end{array}$ & $\begin{array}{c}\mathrm{kO} \\
\left(\mathrm{day}^{-1}\right)\end{array}$ & $\begin{array}{c}\mathrm{kh} \\
\left(\mathrm{day}^{-1}\right)\end{array}$ \\
\hline 1 & 2.044 & 0.2739 & 0.2428 \\
2 & 2.606 & 0.2401 & 0.2039 \\
$2 \mathrm{~b}$ & 2.916 & 0.2148 & 0.1800 \\
3 & 2.610 & 0.2003 & 0.1721 \\
4 & 2.004 & 0.1813 & 0.1557 \\
5 & 2.086 & 0.2336 & 0.2028 \\
6 & 1.557 & 0.2606 & 0.2271 \\
7 & 3.075 & 0.2416 & 0.2135 \\
8 & 2.077 & 0.2551 & 0.2237 \\
9 & 2.420 & 0.2339 & 0.2021 \\
& & & \\
Mean & 2.340 & 0.2335 & 0.2024 \\
\pm SD & 0.468 & 0.028 & 0.027 \\
\hline
\end{tabular}

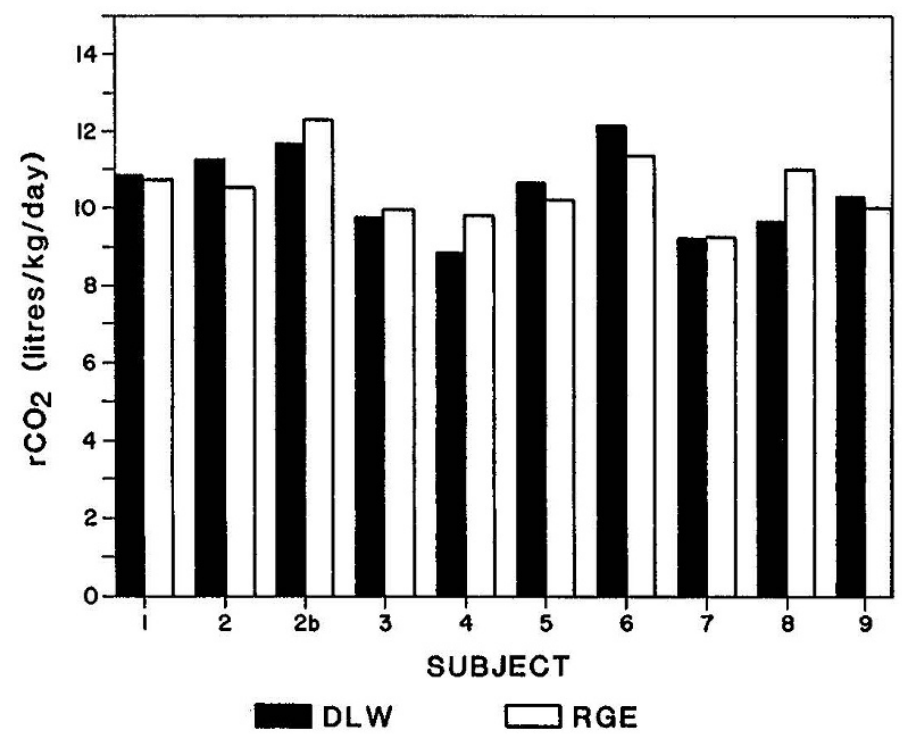

Fig. 1. Carbon dioxide production rates $(\mathrm{rCO} 2)$ measured by doubly labeled water $(D L W)$ and respiratory gas exchange $(R G E)$.

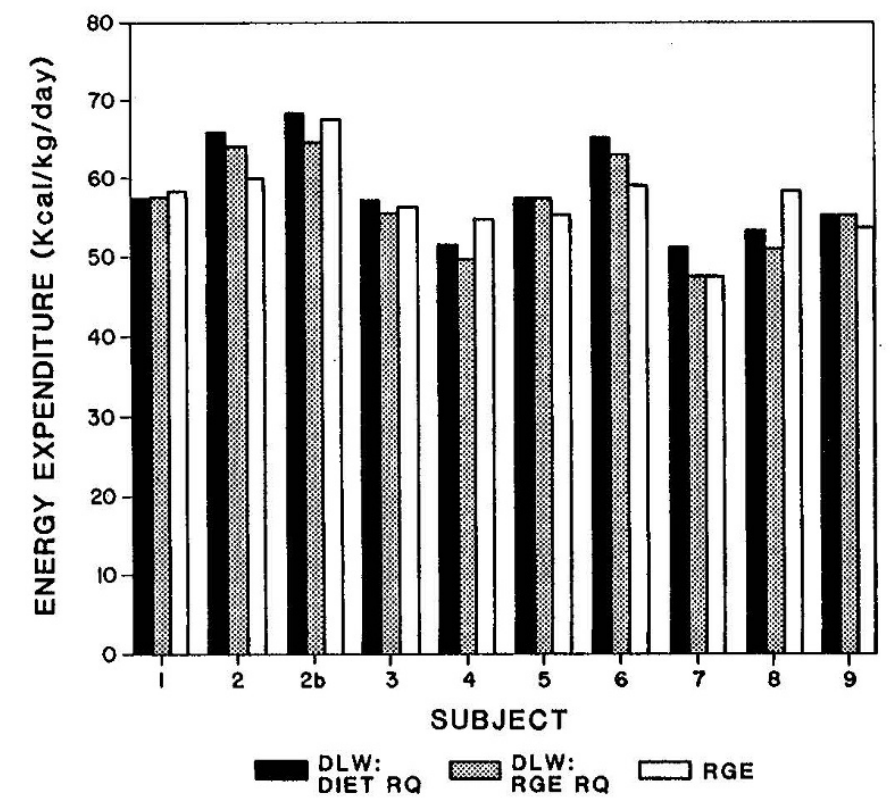

Fig. 2. Energy expenditure measured by doubly labeled water using $\mathrm{RQs}$ from dietary intake (DLW:DIET RQ) and respiratory gas exchange ( $D L W: R G E R Q$ ) data, compared to respiratory gas exchange $(R G E)$.

gas exchange RQ $(56.8 \pm 5.1 \mathrm{kcal} / \mathrm{kg} / \mathrm{day})$ were not significantly different from respiratory gas exchange values $(57.3 \pm 5.1 \mathrm{kcal} /$ $\mathrm{kg} /$ day). Mean relative difference between doubly labeled water:diet RQ and respiratory gas exchange was $-1.6 \pm 5.8 \%$.

In order to determine whether sequestration of isotope during tissue accretion resulted in a systematic error in the doubly labeled water method, we applied simple linear regression analysis to compare the error in the doubly labeled water method against energy retention and change in body water. For each subject, relative error in the measurement of carbon dioxide production $[([\mathrm{rCO} 2$ :doubly labeled water - $\mathrm{rCO} 2$ :respiratory gas exchange]/rCO2:respiratory gas exchange)*100] was compared to energy stored $(\mathrm{kcal} / \mathrm{kg} /$ day $)$ and to change in total body water (1) (Fig. 3). Energy stored was calculated from the difference between metabolizable energy intake and expenditure as measured by respiratory gas exchange. Change in body water was the difference between final and initial total body water as measured by isotope dilution. Correlation coefficients were 0.10 (NS) and 

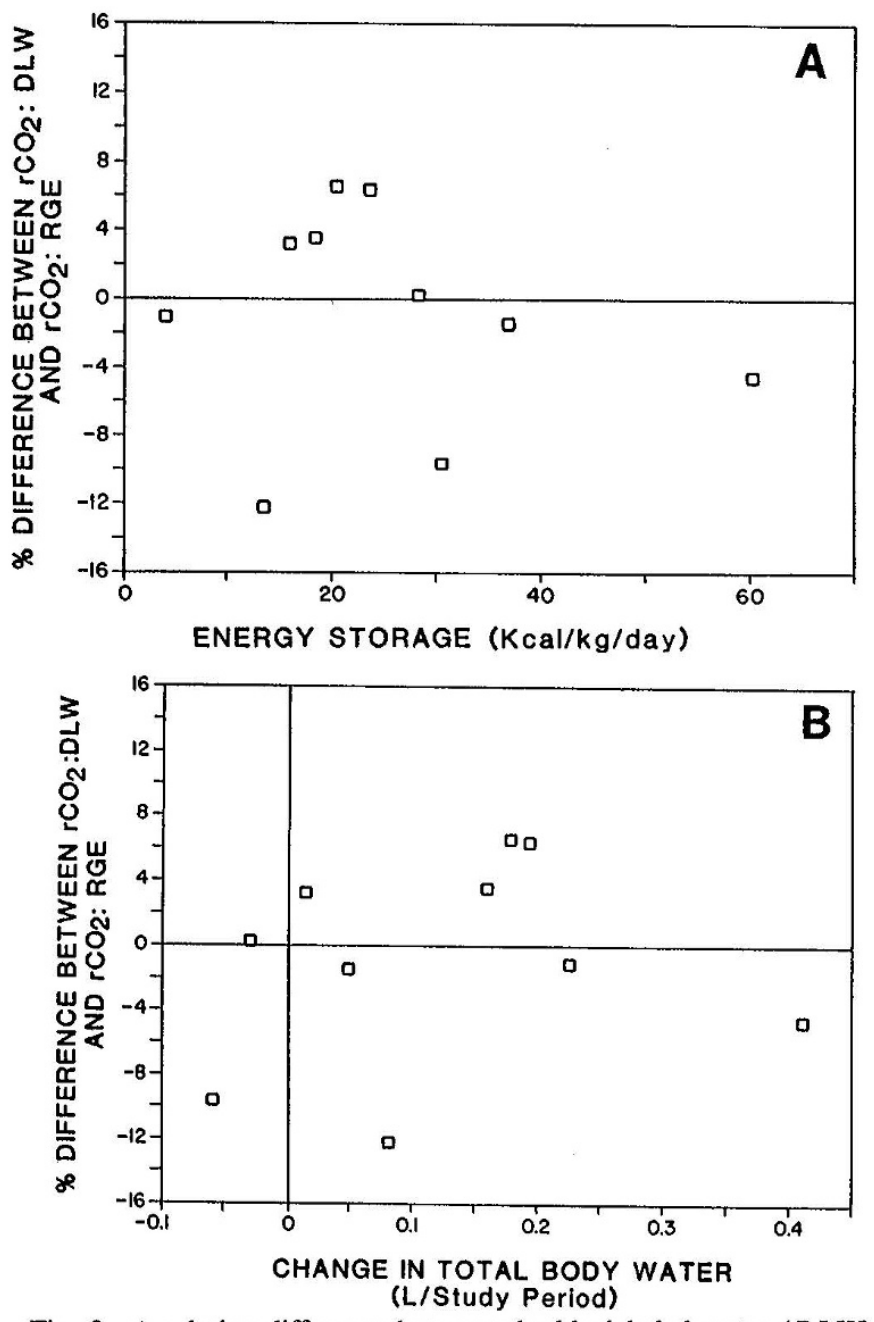

Fig. 3. $A$, relative difference between doubly labeled water $(D L W)$ and respiratory gas exchange $(R G E)$ rates of carbon dioxide production compared with rate of energy storage. $B$, relative difference between doubly labeled water $(D L W)$ and respiratory gas exchange $(R G E)$ rates of carbon dioxide production compared with change in total body water.

-0.22 (NS), respectively, which were not statistically significant $(p>0.4)$.

\section{DISCUSSION}

Energy expenditure measured by double labeled water agreed well with that measured by respiratory gas exchange. The difference between methods was less than $5 \%$ in six of the studies and exceeded $10 \%$ in only one study. This difference reflects random error in both methodologies. The predicted accuracy of the respiratory gas exchange system is $2-3 \%$. In healthy preterm infants, it was found in previous respiratory gas exchange studies that a $6-h$ measurement has an error (CV) of $3.2 \%$ in predicting total daily energy expenditure (14). Although the variability in our group of postsurgical infants may be different from healthy preterm infants, the periodic nature of the present respiratory gas exchange measurements will contribute additional error to that of the analytical system itself. Based on the mean precision of the relative difference between the two methods (5.8\%), it is estimated that the precision associated with doubly labeled water alone was $4.8 \%$.

Assumptions used in derivation of the doubly labeled water equation have been previously published $(15,16)$. We were concerned that three assumptions may be violated in the growing infant resulting in significant systematic errors in the doubly labeled water method.
The first concern was that an infant in an isolet has a different insensible water loss than a clothed adult because the infant has a larger exposed skin surface area. In the present calculations, isotopically fractionated water lost as vapor through skin and lungs was estimated to comprise $18 \%$ of water turnover. For comparison, had we assumed that $50 \%$ of water turnover was subject to isotopic fractionation (16), then $\mathrm{rCO} 2$ from doubly labeled water would have been $16.5 \pm 6 \%$ (mean \pm SD) greater than that measured by respiratory gas exchange. Clearly, using the original assumption of $50 \%$ results in an increased error. Selection of an appropriate value for insensible water loss is central to the accuracy of the doubly labeled water method in infants. The importance of using an appropriate value for isotopically fractionated water loss in the infant was noted by Roberts et al. (6) who performed a simultaneous water balance study to estimate insensible losses. They reported a value of $16 \%$ of water turnover, which is similar to our estimate despite differences in the two groups of subjects. Use of our method for estimating fractionated water loss obviates the need for concurrent water balance studies. It is important in this context that if doubly labeled water is applied to measure energy expenditure in infants in environments which differ from those presently described, adjustments in the factors accounting for isotopically fractionated water vapour loss may be required.

A second concern in application of the doubly labeled water to growing infants was the possible sequestration of isotope, notably deuterium, into accruing tissue. Deuterium sequestration would result in underestimation of energy expenditure by doubly labeled water. To test for this effect, we compared the difference between doubly labeled water and respiratory gas exchange with each of two measures of tissue accretion, the rate of energy storage, and the change in total body water. Absence of statistically significant correlations in each case suggests that sequestration rates were insignificant. Alternatively it cannot be ruled out that both isotopes are being removed at significant rates, but in a ratio that is indistinguishable from water.

Finally, the change in total body water occurring in the growing infant during study was considered as a further source of errors of the doubly labeled water method. To minimize this source of error, the average body water for the study period was assumed to be equal to the average of measurements taken at the beginning and end of the energy expenditure period.

The mean doubly labeled water energy expenditure period was of $5.48 \pm 0.7$ (mean $\pm \mathrm{SD}$ ) days duration. To examine the acceptability of doubly labeled water measurements over a shorter interval, the relative difference in $\mathrm{rCO}_{2}$ between the two methods was calculated using the 2- and 3-day timepoints. Over the period length of $2.35 \pm 0.53$ days the mean difference was $-3.4 \pm 14.3 \%$. Notably, the level of imprecision increased more than 2-fold with the shorter measurement period. This is consistent with predicted theoretical precision levels at these isotope doses using doubly labeled water in the hypothetical neonate over the two periods (17). It is predicted that at most doses an interval of between 6 and 8 days will give the highest precision in the infant.

We were also concerned with the possible effect of decreased gastric motility in the postsurgical infant on isotopic retention. Recovery of label from nasogastric tube aspirates, however, was approximately $1 \%$ of the dose. This low recovery suggests that nasogastric dosing of labeled water is appropriate for doubly water studies in postsurgical infants.

In order to minimize diet-related shifts in natural abundances of deuterium and ${ }^{18} \mathrm{O}$ in body water, subjects were maintained on a consistent nutritional regimen prior to and during study. It was anticipated that the largest shift would be caused by transition from distilled water-based parenteral solutions to tap waterbased oral formulae or breast milk (5). We have recently observed that body water isotopic fluctuations can result in significant errors in estimation of the isotopic enrichment at the endpoint of an energy expenditure period, and thus affect the overall 
accuracy of the doubly labeled water method (Jones PJH, Winthrop AL, Schoeller DA, Filler RM, Heim T, unpublished results).

In nonvalidation studies with doubly labeled water, in which respiratory gas exchange is not measured, $R Q$ would be derived from dietary intake data. In this group of growing infants, energy expenditure measured by doubly labeled water was not significantly different from that measured by respiratory gas exchange measures, even when dietary RQ data were substituted for those obtained by respiratory gas exchange. This finding indicates that for the growing infant, the use of dietary RQ is appropriate when calculating energy expenditure from doubly labeled water. Grossly hypercaloric diets, however, result in dietary RQs which are larger than those calculated from dietary intake. In these cases use of dietary RQ may result in significant error which could invalidate the doubly labeled water method.

In summary, results from doubly labeled water show good agreement with respiratory gas exchange measurements in the group of infants studied. The accuracy and precision of the doubly labeled method for energy expenditure in the present study compare well with validation studies in adults (2-5). This technique shows promise as a useful tool in noninvasive, nonrestrictive accurate determination of energy expenditure in infants over relatively extended periods of time and should compliment current techniques.

Acknowledgments. The authors are grateful for the technical assistance of Ms. Sulachona Chandramowli, Ms. Saro Baskaranworthy, and Ms. Kathleen Van Rassel.

\section{REFERENCES}

1. Heim T 1978 Fetal and neonatal energy metabolism. In: Kerpel-Fronius E, Veghelyi PV, Rosta I (eds) Perinatal Medicine, Budapest, pp 873-902

2. Coward WA, Prentice AM, Murgatroyd PR, Davies HL, Cole TJ, Sawyer M, Goldberg GR, Halliday D, MacNamara JP 1984 Measurement of CO2 and water production rates in man using ${ }^{2} \mathrm{H},{ }^{18} \mathrm{O}$-labelled $\mathrm{H}_{2} \mathrm{O}$; Comparisons between calorimeter and isotope values. In: van Es AJH (ed) Proc from
Euronut Report 5; Human Energy Metabolism: Physical Activity and Energy Expenditure Measurements. Wageningen, The Netherlands, pp 126-128

3. Westerterp KR, Schoffelen PFM, Saris WHM, ten Hoor F 1984 Measurement of energy expenditure using doubly labeled water, a validation study. In: van Es AJH (ed) Proc from Euronut Report 5; Human Energy Metabolism: Physical Activity and Energy Expenditure Measurements. Wageningen, The Netherlands, pp 129-131.

4. Schoeller DA, Webb P 1984 Five day comparison of the doubly labeled water method with respiratory gas exchange. Am J Clin Nutr 40:153-158

5. Schoeller DA, Kushner RA, Jones PJH 1986 Validation of doubly labeled water for measuring energy expenditure during total parenteral nutrition. Am J Clin Nutr 44:291-298

6. Roberts SB, Coward WA, Norhia V, Schlingenseipen KH, Lucas A 1986 Comparison of the doubly labeled water $\left({ }^{2} \mathrm{H}_{2}{ }^{18} \mathrm{O}\right)$ method with indirect calorimetry and a nutrient-balance study for simultaneous determination of energy expenditure, water intake, and metabolizable energy intake in premature infants. Am J Clin Nutr 44:315-322.

7. Hiem T, Putet G, Verellen G, Chessex P, Swyer P, Smith J, Filler R 1981 energy cost of intravenous alimentation in the newborn infant. In: Stern L, Salle B, Fveus-Hansen B (eds) Intensive Care of Newborn III. Masson Salle B, Fveus-Hansen B (eds) Intensi
Publishing Inc, New York, pp 219-238

8. Sauer PJJ, Dane HJ,. Visser HKA 1984 New standards for neutral thermal environment of healthy very low birthweight infants in week one of life. Arch Dis Child 59:18-22

9. Lusk G 1976 The Atwater-Rosa respiration calorimeter. In: The Elements of Science and Nutrition, 4th ed. Academic Press, New York, Inc, p 65

10. Schoeller DA, Ravussin E, Schutz Y, Acheson KJ, Baertschi P, Jequier E 1986 Energy Expenditure by doubly labeled water: validation in humans and proposed calculation. Am J Phys 250:R823-R830

11. Schoeller DA, Peterson DW, Hayes JM 1983 Double comparison method for mass spectrometric determination of hydrogen isotopic abundances. Anal Chem 55:827-832

12. Schoeller DA, van Santen E, Peterson DW, Dietz W, Jaspan J, Klein PD 1980 Total body water measurement in humans with ${ }^{18} \mathrm{O}$ and ${ }^{2} \mathrm{H}$ labeled water. Am J Clin Nutr 38:2686-2693

13. Pinsen EA, Langham WH 1952 Physiology and toxicology of tritium in man. J Appl Physiol 10:108-126

14. Schulze K, Stefanski M, Masterson J, 1986 An analysis of the variables in estimates of bioenergetic variables in preterm infants. Pediatr Res 20:422427

15. Nagy KA $1980 \mathrm{CO} 2$ production in animals: analysis of potential errors in the doubly labeled water method. Am J Phys 238:R466-R473

16. Lifson N, McClintock R 1966 Theory of use of the turnover rates of body water for measuring energy and material balance. J Theor Biol 12:46-74

17. Schoeller DA 1983 Energy expenditure from doubly labeled water: some fundamental considerations in humans. Am J Clin Nutr 38:999-1005 